\title{
Mérimeé, CEuvres complètes, Section I: Littérature, tome 6: Études et traductions de littérature russe
}

\section{Michel Arrous}

\section{(2) OpenEdition}

1 Journals

\section{Édition électronique}

URL : http://journals.openedition.org/studifrancesi/10680

DOI : 10.4000/studifrancesi. 10680

ISSN : 2427-5856

Éditeur

Rosenberg \& Sellier

\section{Édition imprimée}

Date de publication : 1 décembre 2017

Pagination : 567

ISSN : 0039-2944

\section{Référence électronique}

Michel Arrous, « Mérimeé, Eruvres complètes, Section I: Littérature, tome 6: Études et traductions de littérature russe », Studi Francesi [En ligne], 183 (LXI | III) | 2017, mis en ligne le 01 février 2018, consulté le 22 janvier 2021. URL : http://journals.openedition.org/studifrancesi/10680 ; DOI : https://doi.org/ 10.4000/studifrancesi. 10680

Ce document a été généré automatiquement le 22 janvier 2021.

\section{(c) 9 (i) $\Theta$}

Studi Francesi è distribuita con Licenza Creative Commons Attribuzione - Non commerciale - Non opere derivate 4.0 Internazionale. 


\title{
Mérimeé, Euvres complètes, Section I: Littérature, tome 6: Études et traductions de littérature russe
}

\author{
Michel Arrous
}

\section{RÉFÉRENCE}

PROSPER MÉRIMEÉ, CEuvres complètes, Section I: Littérature, tome 6: Études et traductions de littérature russe, sous la coordination d'Antonia Fonyi, textes établis, présentés par JeanLouis Backès, annotés par Jean-Louis Backès et Antonia Fonyi avec le concours de Michel Cadot, Paris, Honoré Champion, 2016, 579 pp.

1 Le tome 6 de la nouvelle édition des Euvres complètes de Mérimée regroupe les articles et les traductions de littérature russe que l'écrivain publia de 1849 à 1870. On trouvera dans les tomes 3 et 4 de la Section Histoire les Écrits sur l'histoire de la Russie. Une fois rappelé l'intérêt de Mérimée pour l'ailleurs russe, Antonia Fonyi marque précisément ce qui distingue l'édition qu'elle coordonne de celle que donna Henri Mongault avec les deux volumes de ses Études russes en 1931-1932, à une époque où sévissait Pierre Trahard. Mongault se serait montré fort sévère voire injuste pour Mérimée traducteur, lui reprochant un «travail ingénieux, mais infécond». Certes Mongault fut impitoyable pour la traduction du Revizor dont il s'est complu à relever les mauvaises lectures, contresens, non-sens et autres bévues (voir Études russes, t. II, pp. 494-530), sans parler des passages où Mérimée, faute de comprendre, abrège ou recourt à des faux-fuyants, ou d'une certaine méconnaissance de la valeur aspectuelle des temps verbaux. Autant de faiblesses qui l'autorisent à affirmer que Mérimée «ne comprend guère la signification profonde de la pièce». Par contraste, on dira que Mongault s'est montré indulgent pour la traduction de Pouchkine, quoiqu'il ait trouvé celle de La Dame de pique «par trop mériméenne». Cela dit, et sans amoindrir en rien la qualité grande de cette nouvelle édition, on peut encore tirer parti de l'introduction (141 pp.) et des notes et 
éclaircissements de Mongault (220 pp.) dont la richesse incite à nuancer l'appréciation selon laquelle tout son travail serait déterminé par «un rapport négatif» à Mérimée.

2 On trouvera dans ce tome les textes rassemblés par Mongault, soit quatre articles sur Pouchkine, Gogol, Tourguéniev, et les traductions de cinq œuvres de Pouchkine ( $L a$ Dame de pique, Les Bohémiens, Le Hussard, Le Coup de pistolet, Boudris et ses fils, ainsi que celle des Trois Fils de Boudris de Mickiewicz), la version intégrale du Revizor, et la traduction de trois nouvelles de Tourguéniev (Apparitions, Le Chien, Étrange histoire). Les éditeurs ont renoncé à publier les traductions révisées ou amendées par Mérimée, ou qui lui ont été attribuées à tort (Le Juif, Pétouchkov, le roman Fumée et Pères et enfants ces deux dernières œuvres ne figuraient pas dans les volumes de Mongault); a été aussi écartée la traduction du Novice de Lermontov révisée par Mérimée et reproduite dans les Études russes.

3 Dans sa présentation intitulée «Mérimée et la découverte de la littérature russe», JeanLouis Backès fait litière d'une idée longtemps accréditée selon laquelle Mérimée serait le découvreur de la littérature russe, comme le prouve l'histoire de la réception de la littérature russe dans la presse et l'édition françaises sous la Restauration et la monarchie de Juillet (une page de la «Bibliographie» aurait pu être réservée aux prédécesseurs de Mérimée; mais il est vrai que le lecteur est invité à consulter la thèse d'Ekaterina Artioukh accessible sur internet). La gloire du traducteur rejaillit sur Pouchkine et poussa Buloz à commander à Mérimée, devenu une autorité en russe, la «tartine» sur Gogol (Nouvelles russes, traduites par Viardot, Les Âmes mortes et L'Inspecteur général, œuvres non encore traduites en 1851). Mongault avait vu «un travail d'écolier» dans la version du Revizor, trente ans plus tard, André Meynieux retouchait "presque toutes les phrases» de La Dame de pique, alors qu'en est-il de Mérimée traducteur? J.-L. Backès rappelle qu'au xix siècle bien des traducteurs se livraient à une véritable récriture (amplifications, ajouts, omissions) et se laissaient parfois emporter par leur imagination. Il est arrivé à Mérimée de recomposer certaines phrases, d'inventer des sens inattendus, d'introduire des nuances étrangères à l'original, et de commettre quelques erreurs amusantes: le fameux contresens de $L a$ Dame de pique (p. 226) dont il se souviendra longtemps, ou un autre, «effrayant», dans Le Chien (p.515). Fautes que J.-L. Backès relève sans la «hargneuse sévérité » de son prédécesseur, dans des pages bien argumentées sur la doctrine et la poétique de Mérimée (pp. 53-67) d'où il ressort que le traducteur, conscient de la difficulté de sa tâche, a fait son devoir. La boutade de Chasles - «en France on traduit $d u$ russe sans savoir le russe» - ne le concerne pas.

4 Avec cette édition conçue dans un esprit et une perspective qui, comme les tomes déjà parus, témoignent du renouveau des études mériméennes, les lecteurs de Mérimée, slavisants ou non, disposent désormais d'un recueil dont l'apport et l'apparat critique équilibré ne peuvent que les satisfaire. 